\title{
Denmark launches big push for protein power
}

A major centre dedicated to protein research is to be built in Denmark thanks to the largest ever donation to Danish research. The Novo Nordisk Foundation, which owns various healthcare and biotechnology companies, this week announced that it would provide 600 million kroner (US\$110 million) to fund the project at the University of Copenhagen.

A core component of the new centre will be a high-throughput facility to express and purify proteins, determine their structure and investigate their properties. The centre will focus on human disease, and will seek to formulate proteins for preclinical tests if they look promising as therapeutics. The university will keep the project's intellectual property, says vice-dean Birgitte Nauntofte.

Just as the study of genes scaled up into genomics in the 1990s, so in recent years protein researchers have been upgrading to proteomics. It is a substantial challenge: genes can code for more than one protein, and the products described in genes can be modified after being translated into protein. This means that although the human genome contains some 25,000 protein-encoding genes, a given person's various cells might use up to a million different proteins to do different things at different times in the course of a life. To crank up the complex- ity further, the proteins work in coordinated teams, requiring their relevant members to be in the right place at the right time if they are to generate the right response.

The Novo Nordisk Foundation Center for Protein Research will have five principal investigators, two of whom have already been appointed. One is Matthias Mann, a director at the Max Planck Institute of Biochemistry in Martinsried near Munich. Mann is a pioneer of protein mass spectrometry, a key proteomics technology. This technique, which smashes proteins into tiny fragments before reconstructing them by computer for identification and further study, benefits from the sort of large-scale computing power and bioinformatics capability a large centre can provide. Mann will not quit his current position but will oversee independent groups working on biological mechanisms such as signal transduction and on stem-cell biology, particularly in relation to diseases such as cancer.

The other lead investigator so far named is Søren Brunak, from the Technical University of Denmark in Copenhagen. Brunak runs one of the largest bioinformatics departments in Europe. At the new centre he will focus on integrating what is known about creatures' physical characteristics with proteomic and genomic information in order to understand

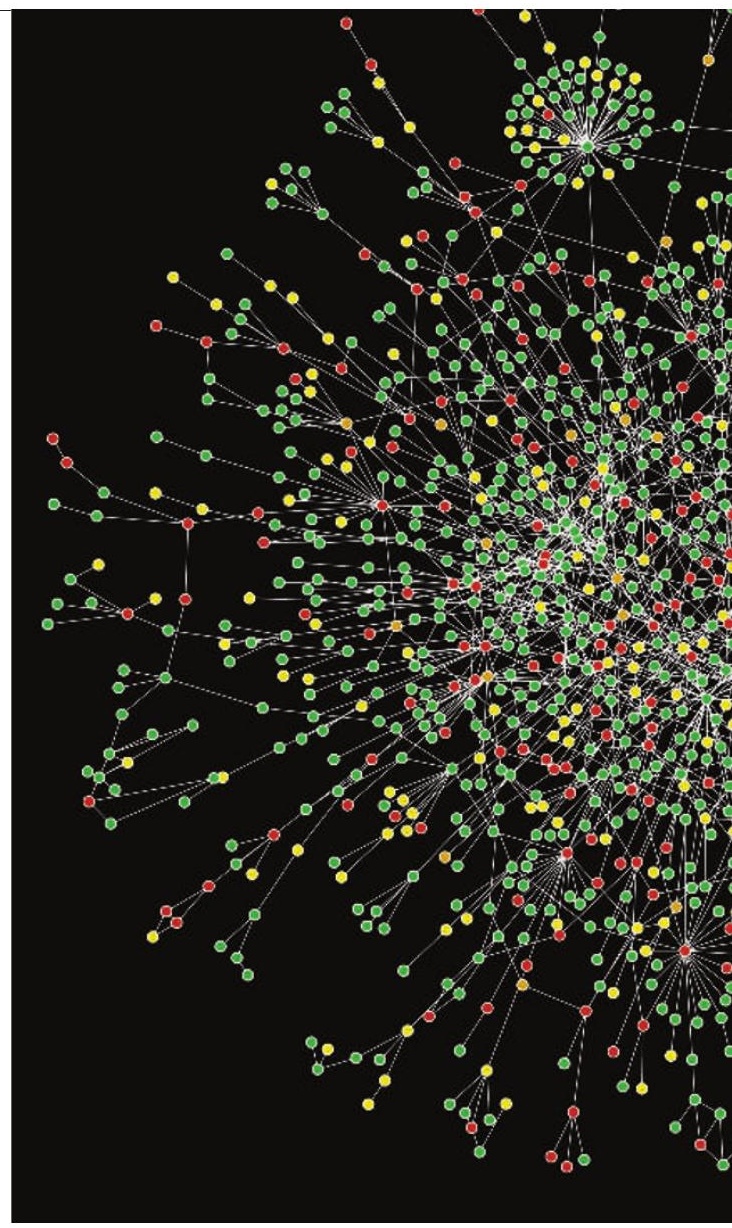

how different protein complexes may relate to disease. "We'll have access to Scandinavian biobanks and electronic patient records renowned for their high quality," says Brunak, "and we'll find more by text mining scientific publication databases."

Mann and Brunack already collaborate in the Interaction Proteome Project, which is funded by the European Commission. "We've merged our skills before - for example we've created

\section{Rapid sequencer puts virus in the frame for deaths}

The discovery of a virus that may have killed three transplant recipients in Australia could mark a dramatic acceleration in the speed at which new pathogens can be identified. But it raises concerns that the ease with which such suspects can now be found could lead to researchers overlooking the need to firmly establish them as the cause of the disease in question. Fingering the wrong microbe could lead to inappropriate treatment or divert attention away from the real cause.
The three patients received organs from a single donor in Melbourne in December 2006. By January all three were dead. Ian Lipkin of Columbia University's Mailman School of Public Health in New York, who specializes in identifying new pathogens, heard about the case and collaborated with the Australian researchers who first took it on. After looking

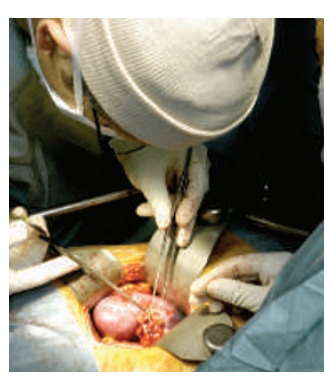

Transplanted organs can carry viruses. for thousands of telltale signs of known pathogens without success, Lipkin, who sits on the advisory board of 454 Life Sciences in Branford, Connecticut, decided to use the company's technology to sequence genes from samples that had been filtered to enrich their non-human DNA component.

Roughly one month and 
